\title{
PACKAGING ELEMENTS AND THEIR INFLUENCE ON CONSUMERS' BUYING BEHAVIOUR
}

\author{
*Senthil, $\mathbf{S}$ and Natarajan, G \\ Department of Business Administration, Annamalai University \\ Department of Business Administration, Directorate of Distance Education, \\ Annamalai University \\ DOI: http://dx.doi.org/10.24327/ijrsr.2017.0803.0116
}

\section{ARTICLE INFO}

\section{Article History:}

Received $17^{\text {th }}$ December, 2016

Received in revised form $21^{\text {st }}$

January, 2017

Accepted $05^{\text {th }}$ February, 2017

Published online $28^{\text {th }}$ March, 2017

\section{Key Words:}

Packaging, Labeling, Color, Innovation, wrapper design

\begin{abstract}
Packaging is considered as one of the important factors of a product. A good packaging to protect the product from various damages. Apart from that packaging it sends some information to the consumers. The basic aim of this study is to determine influence of packaging elements' on consumer's buying behaviour. This research also identifies the relationship between the dependent and independent variables. This is a primary research and data has been collected through questionnaire and for analysis purpose using SPSS software. In this study samples of 150 respondents has been collected and analyzed. According to the findings of the research study, it has been observed that the packaging is the most important factor. It is further concluded that the packaging elements like Colour, Packaging material, Design of Wrapper and innovation are more important factors when consumers make any buying decision. It has also been concluded that the Packaging is one of the most important and powerful factor, which influences consumer's purchase decision.
\end{abstract}

Copyright (C) Senthil, $\mathbf{S}$ and Natarajan, G, 2017, this is an open-access article distributed under the terms of the Creative Commons Attribution License, which permits unrestricted use, distribution and reproduction in any medium, provided the original work is properly cited.

\section{INTRODUCTION}

The consumer's buying behaviour is stimulated by different factors and one such factor is packaging. Packaging includes packaging quality, color, wrapper, and other characteristics. Packaging is a whole package that becomes an ultimate selling proposition, which stimulates impulse buying behaviour. Packaging increases sales and market share and reduces market and promotional costs. Packaging has become itself a sales promotion tool for the organizations. According to Rundh (2005) package appeals consumer's attentiveness towards a certain brand, increases its image, and stimulates consumer's perceptions about product. Furthermore, packaging conveys distinctive value to products (Underwood, 2003; Silayoi, \& Speece, 2007), packaging works as an instrument for differentiation, and helps consumers to decide the product from wide range of parallel products, packaging also stimulates customer's buying behaviour (Wells, Farley \& Armstrong, 2007).

Several studies have been done previously showing that there is no agreement on overall classification of packaging material and package elements. There is also disagreement regarding the methods of package impact on consumer's buying behaviour decision. Several researchers attempt to examine all potential elements of packaging and their effect on consumer's buying decision; however others focus on distinct elements of packaging and their influence on consumer purchasing behaviour (Ampuero \& Vila, 2006; Madden, Hewett, \& Roth, M, 2000; Underwood, Klein, \& Burke, 2001; Bloch, 1995). Furthermore, some researchers explore the impact of packaging and its features on consumer's whole purchase decision (Underwood, Klein, \& Burke, 2001), whereas, some others - on each step of consumer's decision making process (Butkeviciene, Stravinskiene, \& Rutelione, 2008).

Brand image and advertisement have strong positive influence and significant relationship with Consumer's buying behaviour. People perceive the brand image with positive attitude. Study depicted that teenagers in Gujranwala are more conscious about their social status so they prefer branded products and advertisement affects on their Consumer Buying Behaviour positively (Malik, Ghafoor, Iqbal, Ali, Hunbal, Noman, and Ahmed, 2013).

The purpose of this research is constructed on hypothetical analysis of packaging components and their influence on consumer's buying behaviour decision. This empirical study

\footnotetext{
${ }^{\star}$ Corresponding author: Senthil, $S$

Department of Business Administration, Annamalai University Department of Business Administration, Directorate of Distance Education, Annamalai University
} 
uncovers the features, which are having the eventual influence on consumer's choice, when multiple and different choices are available.

\section{Objectives}

- To identify the elements, which should be highlighted while design the packaging.

- To check the relationship of packaging elements on the buying behaviour.

\section{Research Question}

To identify the role of packaging on consumer buying behaviour decision

\section{Background of the Study}

Packaging acts multidimensional functions. It offers knowledge about the product and organization, a technique to communicate with consumers and safeguard to the quality of product (Silayoi \& Speece, 2007). According to Rita Kuvykaite1 (2009) the study reveals the self-service and changing consumers' lifestyle having the ultimate effect on consumer choice. Increase in impulse buying behaviour labeling is also communicating to the customer.

Saeed, Lodhi, Mukhtar, Hussain, Mahmood and Ahmad (2013), integrate the brand image, brand attachment and environmental effects and their impact on consumer purchase decision. Results elaborates that brand image don't have a positive relation with purchase decision, brand attachment has a moderate positive relation with purchase decision and environmental effects but don't have a positive relation with purchase decision.

The consumers purchase more quantity of the products, after looking a well-labeled product. Therefore labeling influences the consumer buying behaviour, but there are some other factors also, which influence the consumer buying behaviour (Saeed, Lodhi, Rauf, Rana, Mahmood \& Ahmed, 2013).

In recent times, people are becoming more concerned towards green purchasing because of a grown consciousness for environmental protection. Green purchasing is essentially the act of buying environmental friendly products. The research model in this study examines the consequences of predictor variables (environmental concern, organizational green image and environmental knowledge) upon criterion variable (green purchase intention) with the moderating effect of perceived product price and quality (Underwood, 2003; Rettie \& Brewer, 2000; Barber, Almanza, \& Donovan, 2006). Adelina \& Morgan (2007) conclude that Packaging could be treated as one of the most valuable tool in today's marketing communications; Packaging has an important impact on consumers buying behaviour. The impact of packaging and its elements can impact the consumer's purchase decision.

According to Karbasivar \& Yarahmadi (2011), more apparel impulse buying and promotional approaches (cash discount) usage between sample, as well as in-store form display (window display) has important role to encourage consumers to buying impulse. They can gift complementary products to encourage consumer to buying impulse. Also sealers can increase apparel impulse buying with decorating their stores in modern style and use attractive lights and colours. The result of the study proves that there is a pivotal relationship between window display, credit card, promotional activities (discount, free product) and consumer impulse buying behaviour (Alice, 2006).

According to Erzsebet \& Zoltan (2007) both the qualitative and quantitative research showed that respondents adopted similar risk reduction strategies in their purchase of baby care products. This research investigated consumer perceptions and buying behaviour of baby care products. The results of the primary research showed that consumers' needs satisfied with the product in terms of reliability and performance and packaging.

According to Butkeviciene, Stravinskiene and A. Rutelione (2008), impulse buying is indeed a relevant factor in CE retailing, thus justifying the use of sales packaging. However, optimization is still important. From an economical and environmental perspective it is very costly to apply sales packaging (with additional material use and transport volume) to products that do not need them, or to apply them in an ineffective way.

Saeed, Lodhi, Mukhtar, Hussain, Mahmood and Ahmad (2011), integrate the brand image, brand attachment and environmental effects and their impact on consumer purchase decision. Results elaborates that brand image don't have a positive relation with purchase decision, brand attachment has a moderate positive relation with purchase decision and environmental effects but don't have a positive relation with purchase decision.

\section{RESEARCH METHODOLOGY}

In order to achieve the above mentioned objectives the following methodology has been adopted. This type of research is descriptive study, because the nature of the data is to collect the description about the respondents and their opinion about packaging.

\section{Variables used in the study}

- Consumer Buying Behaviour

- Packaging color

- Packaging Material

- Design of wrapper

- Innovation

\section{Tools of Data Collection}

In order to find data on role of packaging on consumer buying behaviour, the data were collected with the help of a questionnaire which consists of different variables.

\section{Sampling Technique \& Sample}

The population of this study is the students in educational institutions, and the sample has been collected from post graduate business administration students of a reputed University in Tamilnadu. A sample size of 150 students has been taken for conducting the study by using simple random sampling.

\section{Measures}

The questionnaire consists of different types of questions including dichotomy, multiple choice and Likert scale. All the 
questions were measured in five point Likert scale where from strongly agree to strongly disagree. There were atleast 13 questions in the survey obtaining data for one variable and some questions were directly obtaining with no complications.

\section{Data Analysis \& Findings}

The results of descriptive analysis show as follows:

Table 1 Mean and Standard Deviation of study variables

\begin{tabular}{cccccc}
\hline & N & Minimum Maximum & Mean & Std. Deviation \\
\hline Buying Behaviour & 150 & 1 & 5 & 3.74 & 0.931 \\
Packing Color & 150 & 1 & 5 & 3.65 & 0.944 \\
Quality Packing & 150 & 1 & 5 & 3.75 & 0.925 \\
Wrapper Design & 150 & 1 & 5 & 3.69 & 0.897 \\
Packing Innovation & 150 & 1 & 5 & 3.65 & 0.965 \\
\hline
\end{tabular}

In the above table the minimum values, maximum values, mean values and the values of standard deviation of all the Variables have been shown. Mean value provides the idea about the central tendency of the values of a variable. Number of observations of each variable is 150 . Standard deviation and the extreme values (minimum in comparison - to Maximum value) gives the idea about the dispersion of the values of a variable from its mean value. The Minimum value is 1 while the Maximum value is 5. For buying behaviour, the Mean value is 3.74 with standard deviation of 0.931 . The mean value for packaging color is found to be 3.65 with the standard deviation of 0.944 . For packaging quality, the values can be deviated by 0.925 , which means that the mean value can varied by +0.925 or -0.925 . The mean value is 3.75. Wrapper design has mean value of 3.69 with standard deviation of 0.897 , and packaging innovation has mean value of 3.65 with standard deviation of 0.965. The result shows that all the factors are having equal importance as far as packaging is concerned.

Table 2 Pearson correlation between variables

\begin{tabular}{ccc}
\hline \multirow{2}{*}{ Variables } & \multicolumn{2}{c}{ Buying behaviour } \\
\cline { 2 - 3 } & Pearson correlation & Sig. \\
\hline Packing Color & 0.589 & $<0.001$ \\
Quality Packing & 0.539 & $<0.001$ \\
Wrapper Design & 0.421 & $<0.001$ \\
Packing Innovation & 0.551 & $<0.001$ \\
\hline
\end{tabular}

\section{Hypothesis: 1}

H1: there is relationship between Buying Behaviour and Packing color

Table 2 represents the table of correlations. Where two variables - buying behaviour and Packing color - are positively correlated $(\mathrm{r}=0.589, \mathrm{p}=0.000149)$. There is moderate relation between these two variables, which is significant. So Hypothesis is accepted. So we can say that the attractive packaging color can attract consumer. Consumer likes colourful packaging. It also implies that using attractive colors in packaging we can grab customer attention.

\section{Hypothesis: 2}

$\mathrm{H} 2$ : there is relationship between Buying Behaviour and Quality of Packing.

Table 2 represents the table of correlations. Where two variables buying behaviour and Quality of Packing are positively correlated $(\mathrm{r}=0.539, \mathrm{p}=0.000145)$. There is moderate relation between these two variables, which is significant, So, H2 cannot reject. The result is clears that the consumer also evaluates the products on the behalf of its packaging quality. Customer preferes the better quality of package.

\section{Hypothesis: 3}

H3: there is relationship between Buying Behaviour and Wrapper Design.

Table 2 represents the table of correlations. Where two variables buying behaviour and Wrapper Design are positively correlated $(\mathrm{r}=0.421, \mathrm{p}=0.000149)$. There is moderate relation between these two variables, which is significant. Therefore, Hypothesis: H3 is accepted.

\section{Hypothesis: 4}

H4: there is relationship between Buying Behaviour and Packing Innovation.

Table 2 represents the table of correlations between two variables buying behaviour and Innovation, which is positively correlated $(\mathrm{r}=0.554, \mathrm{p}=0.000145)$. There is moderate relation between these two variables, which is significant. So, there is a significant relationship between Buying Behaviour and Packing Innovation.

\section{CONCLUSION AND RECOMMENDATION}

\section{Conclusion}

In todays' marketing communications, packaging could be treated as one of the most valuable tool; hence, it is necessary to do more detail analysis of its elements and an impact of those elements on consumer's buying behaviour. Appropriate and vivid picture or packaging color, delivers consumers a happy feeling, or an easy handle /open /dose /dispose, package shape. All these elements contribute each important effort to catch consumer's attention and interest. Besides each element's single function, we think that a good combination of these elements may lead the product more eye-catching and attractive. Analyzing an importance of its separate elements for consumer's choice reveals the impact of packaging and its elements on consumer's purchase decision. For this purpose main package's elements has been identified as graphic, color, size, form, and material of packaging, wrapper design, innovation while product information, producer, country-oforigin and brand are considered as important ones. Moreover, the impact of package elements on consumers purchase decisions has been evaluated, and it is concluded that it depends on the consumer's involvement level, time pressure or individual characteristics of consumers.

It has been empirically tested, the proposed research model, package elements, which are having the ultimate effect on consumer choice; in a case of different products from group of convenience goods were available. It has also revealed that elements of packaging are the most important for consumer's purchase decision. For a major part of consumers' attraction was a size of package and material are the main visual elements, whereas, product information is also the main verbal elements when purchasing milk and washing-powder. Results analyzing the impact of package elements on consumers purchase decisions, depending on level of involvement correspond with those of theoretical studies and that visual elements of package have relatively stronger influence on 
consumer's purchasing behaviour when they are in the level of "low involvement", in contrary to those who are in the level of "high involvement".

Packaging has a better reach than advertising does, and can set a brand apart from its competitors. It promotes and reinforces the purchase decision not only at the point of purchase, but also every time the product is used. Packaging in different serving sizes can extend a product into new target markets or help to overcome cost barriers. Packaging can even drive the brand choice (especially in the context of children's products). This research has found that different packaging cues impact and' how a product is perceived. Often the packaging is perceived to be part of the product and it can be difficult for consumers to separate the two (the concept of gestalt). Aspects such as packaging color, typography, illustrations and graphics can influence how a product is perceived. According to this research, it is concluded that most consumers like the product quality after they purchased their desired packaged product. Based on those facts, we cannot say there is a $100 \%$ equal relationship between good package and good product quality, but there is a positive thinking and trend about well-designed package shows high product quality.

As a matter of fact, people are becoming more and more demanding; packaging has been gradually shown its important role in a way to serve consumers by providing information and delivering functions. With its different functionality to ease and to communicate with consumers, there is no doubt about increasingly important role of packaging as a strategic tool to attract consumers' attention and their perception on the product quality. New product manufacturers mostly use the labels in their products. Basically they describe that when it was made, where it was made, how it was made, what it contains, how to use it etc. Furthermore, they believe that labels on the products properly guide the consumers. The information given in the label and its value have to be highlighted while promoting the product in the market. It must also be a more useful technique

\section{Recommendation}

- It is highly recommended to the marketing and business units that they should pay proper attention for good packaging. If they accept or introduce the poor packaging then it could be one of the reasons of product failure in the market. It is necessary to set the packaging standard and to implement strategy accordingly for better protection and promotion of a product.

- Researcher believes that culture difference does have an impact on companies' initiatives to design the product package, for instance, during our research; the choices of packaging colors are quite different between the West and Far East. Thus, it is recommended that it is important for international companies to take a consideration of culture differences when they design the product package in different parts of the World.

- It is finally recommended that the marketers of the industry should not consider the packaging is the solely factor for the success of any product, therefore, they should also take up other important factors of the marketing while they are launching new products or revitalize old products.

- It is also recommended to other researchers when they take up packaging then they should also consider other factors and dimensions of marketing as well.

\section{References}

Rundh, B., 2005. The multi-faceted dimension of packaging. British Food Journal, 107 (9), 670-684.

Underwood, R. L., 2003. The communicative power of product packaging: creating brand identity via lived and mediated experience. Journal of Marketing Theory and Practice, winter, 62-76

Silayoi, P., \& Speece, M., 2007. The importance of packaging attributes: a conjoint analysis approach. European Journal of Marketing, 41 (11/12), 1495-1517.

Wells, L.E., Farley, H., \& Armstrong, G.A., 2007. The importance of packaging design for own-label food brands. International Journal of Retail \& Distribution Management, 35 (9), 677-690.

Butkeviciene, V., Stravinskiene, J., \& Rutelione, A., 2008. 'Impact of consumer package communication on consumer decision making process', Inzinerine EkonomikaEngineering Economics (1), pp. 57-65.

Ampuero, O., \& Vila, N., 2006. Consumer perceptions of product packaging. Journal of Consumer Marketing, 23(2), 100-112.

Madden, T. J., Hewett, K., \& Roth, M. S., 2000. Managing images in different cultures: A cross-national study of color meanings and preferences. Journal of International Marketing, 8(4), 90-107.

Underwood, R.L., Klein, N.M., \& Burke, R.R., 2001. Packaging communication: attentional effects of product imagery. Journal of Product \& Brand Management, 10 (7), 403-422.

Bloch, P.H., 1995. Seeking the ideal form: product design and consumer response. Journal of Marketing, 59 (July), 1629.

Malik, E.M., Ghafoor, M.M., Iqbal, K.H., Ali, Q., Hunbal, H., Noman, M., and Ahmed, B., 2013. Impact of Brand Image and Advertisement on Consumer Buying Behaviour. World Applied Sciences Journal 23 (1): 117-122.

Rita Kuvykaite, A.D., 2009. Impact of Package Elements on Consumer's Purchase Decision. Economics and Management, pp: 441-458.

Saeed, R., Lodhi, R.N., Rauf, A., Rana, M.I., Mahmood, Z., and Ahmed, N., 2013, Impact of Labelling on Customer Buying Behaviour in Sahiwal, Pakistan. World Applied Sciences Journal 24 (9): 1250-1254.

Underwood, R. L., 2003. The communicative power of product packaging: creating brand identity via lived and mediated experience. Journal of Marketing Theory and Practice, Winter, 62-76

Adelina Broadbridge \& Henry Morgan, 2007, consumer buying behaviour and perception toward retail brand baby products.

Karbasivar, A. and Yarahmadi, H., 2011. Evaluating Effective Factors on Consumer Impulse Buying Behaviour. Asian Journal of Business Management Studies 2 (4): 174-181.

Saeed, R., Lodhi, R.N., Mukhtar, A.M.J., Hussain, S., Mahmood, Z., and Ahmad, M., 
Factors Affecting Consumer Purchase Decision in Clothing Industry of Sahiwal, Pakistan. World Applied Sciences Journal 24 (7): 844-849.

Rettie, R., \& Brewer, C., 2000. The verbal and visual components of package design. Journal of Product Brand Management, 9 (1), 56-70.

Maiksteniene, K., and Auruskeviciene, V., 2008. 'Manufacturer and retailer brand acceptance under different levels of purchase involvement', Inzinerine Ekonomika-Engineering Economics (1), pp. 90-96.

Barber, N., Almanza, B.A., \& Donovan, J.R., 2006. Motivational factors of gender, income and age on selecting a bottle of wine. International Journal of wine marketing, 18 (3), 218-232.

Alice, L., 2006, the power of packaging, United States of America, pp. 186-216.

Ali, Z., Iqbal, A., Jan, M., and Ahmad, A., 2013. Coverage of Pak-U.S. Relations on Issue of Counter Terrorism by U.S. Leading News Magazines, Middle-East Journal of Scientific Research, 15 (10), 1464-1471

Sami, U., Khan, S., Shah, M., and Khan, SA., 2013. Assessment of Key Determinants for Economic Growth in Pakistan (1980-2009). World Applied Sciences Journal 26 (10): 1357-1363.
Hye, Q.Z.A., Siddiqui, M.M., 2010. Are Imports and Exports Integrated in Pakistan? A Rolling Window Bound Testing Approach. World Applied Sciences Journal 9 (7): 708-711.

Ali, H., Chaudhri, S.I., Ali, H., Tasneem, A., and Ali, H., 2013. Human Capital as Determinant of Foreign Direct Investment (FDI) in Pakistan. Middle-East Journal of Scientific Research 17 (7): 877-884.

Singh, A., Sharma, P.K., and Malviya, R., 2011. "Eco Friendly Pharmaceutical Packaging Material" World Applied Sciences Journal, 14(11): 1703-1716.

Alekseev, A.G., 2013. "The Legislative Support of the Fight Against Counterfeit Medicines: The International Legal Aspect" Middle-East Journal of Scientific Research, 16(4): 451-454.

Kuatbayeva, A.A., 2013. "Modeling Situational Room for Healthcare" World Applied Sciences Journal, 26(2): 209212.

Ahmed, Rizwan Raheem, Vishnu Parmar and Muhammad Ahmed amin, 2014. "Impact of Product Packaging on Consumer's Buying Behaviour" European Journal of Scientific Research, 120 (2): 145-157.

\section{How to cite this article:}

Senthil, S and Natarajan, G.2017, Packaging Elements and Their Influence on Consumers' Buying Behaviour. Int J Recent Sci Res. 8(3), pp. 16270-16274. DOI: http://dx.doi.org/10.24327/ijrsr.2017.0803.0116 